\title{
PENERAPAN PENDEKATAN KONTEKSTUAL DENGAN SIMULASI MACROMEDIA FLASH UNTUK MEREDUKSI MISKONSEPSI PESERTA DIDIK
}

\author{
Mawardi Jalil Masri $^{1, \mathrm{a}}$, Nur Aisyah Humairah ${ }^{2, \mathrm{~b}}$, Dewi Sartika ${ }^{3, \mathrm{c}}$ \\ 1,2,3 Program Studi Pendidikan Fisika, Fakultas Keguruan dan Ilmu Pendidikan, Universitas Sulawesi Barat \\ e-mail: 르awardi09jali1@gmail.com, ${ }^{b}$ nuraisyah.humairah@unsulbar.ac.id, ${ }^{c}$ dewi.sartika@unsulbar.ac.id
}

\begin{abstract}
Abstrak
Penelitian ini adalah untuk mengetahui (1) persentase miskonsepsi sebelum diterapkan pendekatan kontekstual dengan simulasi macromedia flash dalam pembelajaran fisika, (2) persentase miskonsepsi setelah diterapkan pendekatan kontekstual dengan simulasi macromedia flash dalam pembelajaran fisika, (3) perbedaan yang signifikan sebelum dan setelah diterapkan pendekatan kontekstual dengan simulasi macromedia flash dalam pembelajaran fisika. Jenis penelitian yang digunakan adalah penelitian pre-eksperiment dengan desain one-group-pretest-posttest. Populasi dalam penelitian ini adalah seluruh peserta didik kelas XI SMA Negeri 1 Sendana. Sampel penlitian diambil dengan teknik sampling purposive, sebanyak 24 peserta didik. Teknik pengumpulan data menggunakan tes pilihan ganda certainly of rensponse index (CRI). Teknik analisis data menggunakan analisis deskriptif dan inferensial. Hasil penelitian menunjukkan bahwa (1) persentase miskonsepsi peserta didik sebelum diterapkan pendekatan kontekstual dengan simulasi macromedia flash sebesar 60,16\% dengan kategori kategori sedang, (2) persentase miskonsepsi peserta didik setelah diterapkan pendekatan kontekstual dengan simulasi macromedia flash sebesar 35,16\% dengan kategori sangat rendah, (3) terdapat perbedaan signifikan antara hasil miskonsepsi sebelum dan setelah diterapkan pendekatan kontekstual dengan simulasi macromedia flash dalam pembelajaran fisika.
\end{abstract}

Kata kunci: Pendekatan kontekstual, Macromedia flash, miskonsepsi, pilihan ganda CRI.

\section{IMPLEMENTATION OF CONTEXTUAL APPROACH WITH MACROMEDIA FLASH TO REDUCE STUDENTS'MISCONCEPTION}

\begin{abstract}
The research was aimed to investigate (1) The large percentage of misconceptions before applied contextual approach with macromedia flash simulation in physics learning, (2) The large percentage of misconception after applied contextual approach with macromedia flash simulation in physics learning, (3) The significant difference before and after application contextual approach with simulation macromedia flash in physics learning. The type of research was used pre-experiment research with one-group-pretest-posttest design. Population in this research was all students of eleventh grade students of SMANegeri 1 Sendana. The sample was taken by purposive sampling technique, as many as 24 students. Data collection techniques was used multiple choice tests certainly of rensponse index (CRI). Data analysis techniques was used descriptive and inferential analysis. The results showed that (1) The percentage of misconceptions of learners before application contextual approach with macromedia flash simulation 60,16\% with medium category, (2) The percentage of misconception learners after applied contextual approach with macromedia flash simulation 35,16\% with very low category, (3) There was significant between misconception result before and after applcation contextual approach with macromedia flash simulation in physics learning.
\end{abstract}

Keywords: Contextual approach, Macromedia flash, misconception, multiple choice CRI. 


\section{PENDAHULUAN}

Fisika dipandang sebagai dasar bagi pembangunan ilmu dan teknologi karena melalui belajar fisika dapat membentuk pola berpikir ilmiah sehingga mata pelajaran fisika sangat diperlukan untuk dipelajari di sekolah. Belajar fisika berarti belajar konsep yang harus dipahami. Dalam fisika banyak membahas tentang alam dan gejalanya, dari yang bersifat nyata hingga yang bersifat abstrak atau hanya berupa teori.

Pemahaman konsep sangatlah penting bagi peserta didik, agar tidak timbul suatu konsep yang salah atau miskonsepsi. Menurut Ibrahim (2012:13)[7] Miskonsepsi adalah ide atau pandangan yang salah tentang suatu konsep yang dimiliki seseorang yang berbeda dengan konsep yang disepakati dan dianggap benar oleh para ahli. Miskonsepsi sering kali terjadi dalam pembelajaran, begitupun dalam belajar fisika. Seperti halnya yang ditemukan di SMA Negeri 1 Sendana.

Pada tanggal 20 Maret 2017, peneliti telah melakukan observasi di Kelas X SMA Negeri 1 Sendana melalui pembagian lembar kuesioner. Dari 8 soal koesioner yang diikuti 27 peserta didik, soal nomor 1 yang mengalami miskonsepsi 4 peserta didik, soal nomor 2 yang mengalami miskonsepsi 9 peserta didik, soal nomor 3 dan 4 yang mengalami miskonsepsi 25 peserta didik, soal nomor 5 yang mengalami miskonsepsi 24 peserta didik, soal nomor 6 yang mengalami miskonsepsi 23 peserta didik, soal nomor 7 yang mengalami miskonsepsi 22 peserta didik, dan untuk soal nomor terakhir yang mengalami miskonsepsi 21 peserta didik. Dari hasil tersebut dapat disimpulkan bahwa miskonsepsi peserta didik kelas $\mathrm{X}$ masih sangat tinggi.

Berdasarkan hasil wawancara dengan guru mata pelajaran di SMA Negeri 1 Sendana ada beberapa masalah yang menjadi penyebab dari tingginya miskonsepsi yaitu kurangnya minat belajar peserta didik khususnya pada pelajaran fisika. Selain itu guru mata pelajaran Fisika kelas $\mathrm{X}$ masih menggunakan metode ceramah serta lebih mementingkan mengajarkan rumus-rumus fisika dalam menyelesaikan soal. Padahal belajar fisika bukan hanya belajar tentang rumus tetapi juga belajar tentang konsep-konsep Fisika. Jika miskonsepsi pada peserta didik kelas X IPA tidak di atasi, pembentukan konsep ilmiah peserta didik dapat terganggu. Hal ini dapat menyebabkan kesulitan belajar dan akhirnya akan bermuara pada rendahnya prestasi belajar. Oleh karena itu miskonsepsi yang terjadi pada peserta didik harus dikurangi atau direduksi.

Salah satu cara untuk mengurangi miskonsepsi peserta didik yaitu menggunakan pendekatan kontekstual. Menurut Sagala (2003:87) [15] Pendekatan kontekstual merupakan konsep belajar yang membantu guru mengaitkan antara materi yang diajarkannya dengan situasi dunia nyata dan mendorong pembelajar membuat hubungan antara materi yang diajarkannya dengan penerapannya dalam kehidupan mereka.

Pernyataan ini didukung hasil penelitian yang dilakukan oleh Ita Viana Dwi dkk, (2013) [4] Mengenai Penerapan Pendekatan Contextual Teaching and Learning (CTL) untuk mengatasi miskonsepsi peserta didik SMP pada materi fotosintesis, menyatakan bahwa persentase ketuntasan hasil belajar kelas VIII-A saat pretest sebesar 3,12\% dan setelah posttest persentase ketuntasan hasil belajar kelas VIII-A meningkat menjadi 90,63\%. Dengan naiknya persentase ketuntasan hasil belajar kelas VIII-A dapat disimpulkan bahwa pendekatan kontekstual dapat mereduksi miskonsepsi.

Selain dari pendekatan kontekstual juga dibutuhkan media pembelajaran yang mendukung untuk mereduksi miskonsepi 
peserta didik. Salah satu media pembelajaran yang tepat untuk digunakan yaitu media pembelajaran dengan menggunakan simulasi berbasis komputer karena simulasi berbasis komputer dapat menjelaskan konsep-konsep fisika yang sifatnya abstrak.

Salah satu Software komputer yang dapat digunakan untuk membuat simulasi adalah Software Macromedia Flash. Menurut Syarif (Prasetia, 2014:29) [13] macromedia flash adalah salah satu future splash animator yang memudahkan pembuatan animasi pada layar komputer dalam menampilkan Gambar secara audiovisual dan lebih menarik.

Pernyataan di atas juga didukung oleh penelitian yang dilakukan Nur Noviana (2016) [12] mengenai pengaruh media simulasi komputer terhadap miskonsepsi peserta didik SMA kelas $\mathrm{X}$ pada konsep fluida statis menyatakan bahwa terdapat pengaruh media simulasi komputer terhadap miskonsepsi peserta didik pada konsep fluida statis. Berdasarkan hasil penelitian Nur Noviana dikrtahui bahwa ranah kemampuan memahami (C2) persentase penurunan miskonsepsi sebesar 26,66\%, pada ranah kemampuan menerapkan (C3) persentase penurunan miskonsepsi sebesar 20,50\%, dan pada ranah kemampuan menganalisis (C4) persentase penurunan miskonsepsi sebesar 11,67\%.

Berdasarkan uraian yang telah dipaparkan di atas, maka peneliti terdorong untuk melakukan sebuah penelitian dengan judul "Penerapan Pendekatan kontekstual dengan simulasi macromedia flash untuk mereduksi miskonsepsi peserta didik kelas XI IPA SMA Negeri 1 Sendana”.

\section{METODE}

\section{Jenis Penelitian}

Penelitian ini menggunakan pendekatan kuantitatif kuantitatif dengan metode eksperimen.

\section{Waktu dan Tempat Penelitian}

Khususnya untuk penelitian kualitatif, waktu dan tempat penelitian perlu dituliskan secara jelas (untuk penelitian kuantitatif, juga perlu).

\section{Target/Subjek Penelitian}

Subjek dalam penelitian ini adalah seluruh peserta didik kelas XI IPA SMA Negeri 1 Sendana tahun ajaran 2017/2018 yang berjumlah 119 orang.

\section{Prosedur}

Prosedur dalam penelitian ini mengikuti desain penelitian Pre-Eksperimen yang menggunakan One-Group Pretest-Posttest Design sebagai berikut:

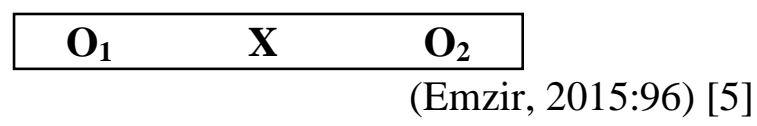

\section{Keterangan:}

$\mathrm{O}_{1} \quad$ : Pengukuran (sebelum diberi perlakuan/pre-test)

$\mathrm{X}$ : Perlakuan (pendekatan kontekstual dengan simulasi macromedia flash)

$\mathrm{O}_{2}$ : Pengukuran (sesudah diberi perlakuan/posttest)

\section{Data, Intrumen, dan Teknik Pengumpulan Data}

Instrumen penelitian yang digunakan dalam penelitian ini adalah instrumen keterlaksanaan RPP dan instrumen certainly of rensponse index (CRI). Intrumen CRI terdiri dari 2 bagian yaitu: (1) pertanyaan tentang konsep dan (2) pernyataan untuk mengetahui kualitas dan kepastian respon yang diberikan ketika menjawab pertanyaan konsep.

Instrumen tes miskonsepsi, sebelum digunakan dinilai oleh 2 orang ahli. Hasil penilaian dari kedua Ahli tersebut kemudian 
dianalisis dengan menggunakan validitas is $\mathbf{2}$ ) secara keseluruhan. Koefisien validitas isi tersebut dihitung berdasarkan rumus berikut:

$$
\text { Validasi isi }=\frac{\mathrm{D}}{(\mathrm{A}+\mathrm{B}+\mathrm{C}+\mathrm{D})}
$$

(Gregory dalam Retnawati, 2016: 33) [14]

Berdasarkan ketentuan dari kesepakatan antar ahli untuk validasi isi bahwa item dengan status D dapat langsung digunakan, untuk item dengan status C dan B akan dikoreksi lagi sebelum digunakan, sedangkan untuk item dengan status A akan langsung dibuang (Humairah, 2010:62) [6]. Adapun kategori validitas isi dapat dilihat pada tabel 1 .

Tabel 1 Kategori Validitas Isi

\begin{tabular}{ll}
\hline Interval & Kategori \\
\hline$>0,8$ & Tinggi \\
$0,4-0,8$ & Sedang \\
$<0,4$ & Rendah \\
\hline
\end{tabular}

(Retnawati, 2016:33) [14]

\section{Teknik Analisis Data}

Teknik analisis data yang digunakan dalam penelitian ini adalah analisis deskriptif dan analisis inferensial.

\section{1) Teknik Analisis Deskriptif}

\section{Perolehan Nilai:}

Untuk mengetahui nilai yang diperoleh peserta didik, maka skor dikonversi ke nilai dengan menggunakan rumus:

$$
\text { Nilai }=\frac{\sum \text { miskonsepsi }}{\sum \text { miskonsepsi }_{\max }} \times 100
$$

(Kusuma, 2014:2) [9]

Dengan kategori sebagai berikut:

Tabel 2 Kriteria Penilaian Persentase

\begin{tabular}{ccl}
\multicolumn{3}{c}{ Miskonsepsi } \\
\hline No & $\begin{array}{c}\text { Persentase } \\
\text { miskonsepsi }\end{array}$ & \multicolumn{1}{c}{ Kategori } \\
\hline 1 & $0 \%-45 \%$ & Sangat rendah \\
2 & $46 \%-55 \%$ & Rendah \\
3 & $56 \%-65 \%$ & Sedang \\
4 & $66 \%-79 \%$ & Tinggi \\
5 & $80 \%-100 \%$ & Sangat tinggi \\
\hline
\end{tabular}

\section{Teknik Analisis Inferensial}

Analisis statistik inferensial digunakan untuk menguji hipotesis penelitian. Sebelum dilakukan pengujian hipotesis terlebih dahulu dilakukan uji prasyarat yaitu uji normalitas.

\section{Uji Hipotesis}

Pengujian hipotesis pada penelitian ini menggunakan uji-t, dengan $\alpha=0,05$. (Arikunto, 2014:82) [2] yaitu:

$$
\mathrm{t}=\frac{\mathrm{Md}}{\sqrt{\frac{\sum \mathrm{xd}^{2}}{\mathrm{~N}(\mathrm{~N}-1)}}}
$$

Kriteria pengujian untuk uji $\mathrm{t}$ adalah sebagai berikut:

$t_{\text {hitung }} \leq \mathrm{t}_{\text {tabel }}$, maka $\mathrm{H}_{0}$ diterima

$t_{\text {hitung }}>t_{\text {tabel }}$, maka $\mathrm{H}_{\mathrm{a}}$ diterima

Uji hipotesis dilakukan untuk menjawab hipotesis penelitian. Hipotesis pada penelitian ini sebagai berikut:

Tidak terdapat perbedaan miskonsepsi peserta didik kelas XI SMA Negeri 1 Sendana yang signifikan setelah diterapkan pendekatan kontekstual dengan simulasi Macromedia Flash.

Terdapat perbedaan hasil peserta didik kelas XI SMA Negeri 1 Sendana yang signifikan setelah diterapkan pendekatan kontekstual dengan simulasi Macromedia Flash.

\section{HASIL DAN DISKUSI}

\section{Hasil Analisis Deskriptif}

Berdasarkan hasil analisis diperoleh miskonsepsi rata-rata pretest 9,58 dan posttest 5,75. Jika skor miskonsepsi dikonversi dalam bentuk persentase nilai miskonsepsi diperoleh pretest 59,875 dengan kategori sedang dan posttest 35,938 dengan kategori sangat rendah. Dilihat dari persentase rata-rata miskonsepsi peserta didik dapat dikatakan bahwa terdapat penurunan miskonsepsi peserta didik setelah diterapkan pendekatan kontekstual dengan simulasi macromedia flush.

Berdasarkan hasil pretest dan posttest 
ditinjau dari jumlah miskonsepsi, jumlah paham konsep dan jumlah tidak paham konsep yang dialami peserta didik kelas XI IPA 2 SMA Negeri 1 Sendana dapat dilihat sebagai berikut:

Tabel 5 Persentase Hasil Pretest dan Posttest Ditinjau Dari Miskonsepsi, Paham Konsep, Dan Tidak Paham Konsep

\begin{tabular}{ccc}
\hline Aspek & Pretest & Posttest \\
\hline Miskonsepsi & $60,16 \%$ & $35,16 \%$ \\
Paham konsep & $29,16 \%$ & $63,02 \%$ \\
Tidak paham & $10,41 \%$ & $1,84 \%$ \\
konsep & & \\
Jumlah & $100 \%$ & 100 \\
& & $\%$ \\
\hline
\end{tabular}

(Sumber: Olahan Data)

Dari tabel diatas, terlihat perbedaan miskonsepsi setelah pretest dan posttest ditinjau dari miskonsepsi, paham konsep dan tidak paham konsep, dari tabel di atas terlihat persentase miskonsepsi peserta didik pada saat pretest sebesar $60,16 \%$ mengalami penurunan sebesar $25 \%$ menjadi $35,16 \%$ pada saat posttest. Persentase Paham konsep peserta didik pada saat pretest sebesar 29,16\% mengalami peningkatan sebesar $33,86 \%$ menjadi $63,02 \%$ pada saat posttest. Persentase tidak paham konsep peserta didik pada saat pretest sebesar $10,47 \%$ mengalami penurunan sebesar $8,63 \%$ menjadi $1,84 \%$ pada saat posttest. Hal ini berarti peserta didik kelas XI IPA 2 SMA Negeri 1 Sendana mengalami penurunan sebesar $25 \%$ setelah menerapkan pendekatan kontekstual dengan simulasi macromedia flash.

\section{Hasil Analisis Inferensial}

Uji Hipotesis

Pengujian hipotesis yang telah diajuhkan dianalisis dengan digunakan uji-t dengan menggunakan taraf ketidakpastian $5 \%$ dan $\mathrm{dk}$ $=5$, dimperoleh $t_{\text {hitung }}=5,48>t_{\text {tabel }}=2,07$, yang berarti pengujian hipotesis berada pada penolakan $\mathrm{H}_{0}$ dan penerimaan $\mathrm{H}_{\mathrm{a}}$ yang berarti terdapat perbedaan signifikan antara miskonsepsi peserta didik kelas XI IPA 2 SMA Negeri 1 Sendana sebelum dan setelah pendekatan kontekstual dengan simulasi macromedia flash. Maksud dari signifikan dalam hal ini adalah pengujian hipotesis meyakinkan dan berarti, sehingga dapat diterima.

\section{SIMPULAN DAN SARAN}

\section{Simpulan}

Berdasarkan hasil penelitian dan pembahasan, maka dapat disimpulkan bahwa :

1) Persentase miskonsepsi peserta didik kelas XI IPA SMA Negeri 1 Sendana sebelum menerapkan pendekatan kontekstual dengan simulasi macromedia flash sebesar $60,16 \%$ dengan kategori sedang.

2) Persentase miskonsepsi peserta didik kelas XI IPA SMA Negeri 1 Sendana setelah menerapkan pendekatan kontekstual dengan simulasi macromedia flash sebesar 35,16\% dengan kategori sangat rendah.

3) Terdapat perbedaan signifikan antara miskonsepsi fisika peserta didik kelas XI IPA SMA Negeri 1 Sendana sebelum dan setelah menerapkan pendekatan kontekstual dengan macromedia flash.

\section{Saran}

Sehubungan dengan hasil yang diperoleh dalam penelitian ini, maka penulis mengajukan saran sebagai berikut:

1) Akan lebih baik jika persediaan LCD projector ditambah untuk lebih memaksimalkan proses pembelajaran.

2) Menyadarkan peserta didik untuk lebih berpartisipasi jika terdapat peserta didik yang kurang berpartisipasi dalam proses pembelajaran.

\section{DAFTAR PUSTAKA}


[1] Ali, Sidin dan Khaeruddin. 2012. Evaluasi Pembelajaran. Makassar: Badan Penerbit UNM

[2] Arikunto, Suharsimi. 2014. Prosedur Penelitian Suatu Pendekatan Praktik. Jakarta: Bumi Aksara

[3] Arsyad, Arie Arma. 2015. Pengembangan Perangkat Pembelajaran Berorientasikan Pendekatan Cooperative Problem Solving Pada Pokok Bahasan Optik Untuk Meningkatkan Hasil Belajar Siswa SMP (Tesis Tidak Dipublikasikan). Surabaya: Universitas Negeri Surabaya

[4] Dwi, Ita Viana dkk. 2013. Mengenai Penerapan Pendekatan Contextual Teaching and Learning (CTL) untuk mengatasi miskonsepsi peserta didik SMP pada materi fotosintesis. Jurnal Pendidikan Sains e-Pensa. Vol. 01:2129

[5] Emzir 2007. Metode Penelitian pendidikan kuantitatif dan kualitatif. Jakarta: Rajawali Pers

[6] Humairah, Nur Aisyah. 2010. Implementasi Kurikulum Tingkat Satuan Pendidikan Dalam Pembelajaran Fisika Pada SMP Negeri Di Kabupaten Polewali Mandar. Tesis: Universitas Negeri Makassar

[7] Ibrahim, Muslimin. 2012. Seri Pembelajaraninovatif Konsep, Miskonsepsi, Dan Cara Pembelajarannya. Surabaya: Unesa Universitas Press

[8] Ibrahim, M. 2005. Assesmen Berkelanjutan. Surabaya: Unipress Unesa

[9] Kusuma, Dani Widia, dkk. 2014. Miskonsepsi Tentang Fotosintesis Pada Siswa Kelas V SDN 4 Trebungan Situbondo tahun pelajaran 2013/2014. Jurnal Universitas Jamber

[10]Mudlofir, Ali dan Evi Fatimatur Rusydiyah. 2015.2 Desain Pembelajaran Inovatif Dari Teori Ke Praktik. Jakarta: Rajawali Pers
[11]Nurdin, Syafruddin dan Adriantoni. 2016. kurikulum dan pembelajaran. Jakarta: Rajawali Pers

[12]Noviana, Nur. 2016. Pengaruh Media Simulasi Komputer Terhadap Miskonsepsi Peserta didik Sma Kelas X Pada Konsep Fluida Statis. Skripsi. UIN Syarif Hidayatullah

[13]Prasetia, Oktavianes Andri. 2015. Efektivitas Penggunaan Macromedia Adobe Flash Player 6 Untuk Meningkatkan Kemampuan Mengenal Angka Pada Anak Tunagrahita Ringan Grobogan Tahun Ajaran 2014/2015. Skripsi. UNESA

[14]Retnawati, Heri. 2016. Analisis Kuantitatif Instrumen Penelitian. Yogyakarta: Parama Publishing

[15]Sagala, Syaiful. 2010. Konsep dan makna pembelajaran. Bandung: Alfabeta

[16]Subaweh, Ahmad Maskur. 2016. Penerapan Pendekatan Kontekstual Dalam Pembelajaran Menulis Teks Berita Pada Peserta didik Kelas VIII MTs Nurul Huda Kalibuntu Kecamatan Losari. STIKIP NU Indramayu vol. VII:39-43

[17]Sugiyono. 2005. Statistika Untuk Penelitian. Bandung: Alfabeta

[18]Susetyo, Budi. 2017. Statistika untuk Analisis Data Penelitian. Bandung: Refika Aditama. 